\title{
Metalistas x papelistas: \\ origens teóricas e antecedentes do debate entre \\ monetaristas e desenvolvimentistas
}

\section{Palauras-chave \\ economia brasileira, pensamento econômico latino- americano, desenvolvimento econômico, bulionismo, controvérsias monetárias.}

Classificação JEL B10, E42, N16, N26

\section{Keywords}

Brazilian economy, LatinAmerican economic thought, economic development, bullionism, monetary controversies.

JEL Classification $B 10, E 42$, N16, N26

\section{Resumo}

$\mathrm{O}$ artigo analisa o debate entre metalismo e papelismo, ocorrido no Brasil, na segunda metade do século XIX, e defende que esta última foi uma das correntes que contribuíram para a gênese do desenvolvimentismo. Para tanto, retoma as controvérsias monetárias da Inglaterra, desde o início daquele século, e nelas identifica as origens teóricas do debate brasileiro, com destaque especial à questáo referente à neutralidade ou não da moeda. A seguir, mostra como esse foi adaptado às peculiaridades da economia brasileira, com ênfase à opção dos papelistas pelo crescimento, rompendo com a ortodoxia da época. A influência no desenvolvimentismo nascente é trabalhada empiricamente por meio de manifestaçóes assumidas por Getúlio Vargas, já que esse foi o personagem central do Estado desenvolvimentista, que marcou a experiência histórica brasileira após 1930 .
Pedro Cezar Dutra Fonseca Universidade Federal do Rio Grande do Sul Maria de Lourdes Rollemberg Mollo Universidade de Brasília

\section{Abstract}

The paper analyzes the debate between metallism and "paper moneyism" which took place in Brazil in the second half of the 19th century and advocates that the latter was one of the currents that contributed to the genesis of developmentalism. In order to do so, it reviews the monetary controversies in England since the beginning of that century. Based on them, it identifies the theoretical origins of the Brazilian debate, highlighting the issue that refers to the neutrality or nonneutrality of money. Next, it shows how this question was adapted to the peculiarities of the Brazilian economy, emphasizing the "paper moneyists"'option for growth, departing from the orthodoxy of that time. The influence upon the fledgling developmentalism is empirically studied based on the speeches of Getulio Vargas, since he was the central character of the developmentalist State that was central to the Brazilian post-1930 historical experience. 


\section{1_Introdução}

As controvérsias entre economistas acompanham a história do pensamento econômico desde seu nascedouro. Alguns argumentos tendem a ser repetir no tempo, por serem decorrentes de supostos teóricos ou postulados básicos de cada teoria. Aprende-se sempre, porém, revisitando suas origens, posto que alguns argumentos passam a ser mais bem apreciados com a distância do tempo e também porque os condicionantes históricos da predominância de algumas teorias sobre outras podem ser mais bem percebidos.

Neste artigo, analisaremos antigas controvérsias sobre economia e política monetária na Inglaterra do século XIX, de forma a melhor entender seu reflexo no Brasil da época e, subsidiariamente, tirar conclusóes sobre as raízes monetárias do desenvolvimentismo. Para isso, descreveremos, no primeiro item do artigo, as controvérsias entre bulionistas e antibulionistas e entre a Currency School e a Banking School, destacando seus principais argumentos e conclusóes, em particular no que se refere ao debate sobre a neutralidade ou não neutralidade da moeda. Em seguida, no segundo item, analisaremos o reflexo desse debate no Brasil, acompanhando as discussões entre metalistas e papelistas. Destacaremos, entáo, a posição de cada um dos grupos e a análise dos problemas que o padrão-ouro apresentava para o andamento da economia brasileira, como forma de explicitação da não neutralidade da moeda. Assim fazendo, buscaremos justificar, no terceiro item, a origem papelista do desenvolvimentismo. Ao final, apresentamos um sumário das principais conclusôes.

\section{2_As controvérsias monetárias da Inglaterra no século XIX}

O século XIX conheceu duas controvérsias monetárias famosas na Inglaterra: dos bulionistas X antibulionistas e da Currency School X Banking School. Do lado ortodoxo da primeira controvérsia, o dos bulionistas, encontrava-se Ricardo, como seu representante mais proeminente, inspirando com seus argumentos alguns representantes ortodoxos da Currency School, anos mais tarde. Também podemos citar Wheatley e Thornton, este último mais moderado (O'Brien, 2004), como representantes dos bulionistas. No polo heterodoxo, entre os antibulionistas, poderemos citar, por exemplo, Bosanquet, Torrens e Boase.

Quanto aos representantes da controvérsia entre a Currency School e a Banking School, temos agora, no polo mais ortodoxo da primeira, personagens como Torrens, antigo antibulionista, o 
1 A tradução dos textos em inglês foi feita livremente, razão pela qual, em nota de pé de página, constam as citaçóes originais em inglês como a que se segue. "It is evident, then, that a depreciation of the circulating medium is the necessary consequence of its redundancy; and that in the common state of the national currency this depreciation is counteracted by the exportation of the precious metal".

2 Quanto ao papel monetário dos country banks, esse era visto como podendo ser controlado pelo Banco da Inglaterra. que mostra certa ortodoxização das discussôes, o que reforçaremos ao longo da análise adiante. Além de Torrens, destaca-se o nome de Lord Overstone. Tooke (1840), que é o representante mais proeminente da Banking School, podendose citar também como participante da Banking School o nome de Fullarton.

A primeira controvérsia ocorreu entre 1797 e 1825. A grande preocupação dos bulionistas era com o controle da oferta monetária como instrumento para controle de preços, defensores que eram da Teoria Quantitativa da Moeda (TQM). Segundo eles, o prêmio sobre o bullion (ouro em espécie), em relação ao valor do ouro cunhado (mint price) era sinal de excesso de emissão de notas bancárias (O’Brien, 2004). Esse argumento, além de lhes valer o título de bulionistas, fazia-os crer que a inflação era fruto de excesso de emissão. Esse poderia ser constatado por sintomas como a queda da paridade do país emissor e a depreciaçáo do papel moeda relativamente ao bullion. Dizia Ricardo (1951, p. 63) a esse respeito:

É evidente, então, que a depreciação do meio circulante é a consequência necessária da sua redundância; e que no estado comum da moeda nacional a depreciação é neutralizada pela exportação de metais preciosos. ${ }^{1}$
Tratava-se, pois, de um problema causado pela administraçáo monetária por parte do Banco da Inglaterra, que emitia em excesso o papel-moeda ou papel-crédito (Dean, 1980), ${ }^{2}$ Cabia, portanto, controlar a emissão de notas bancárias, para o que se poderia contar, por exemplo, com as operaçóes de mercado externo. Por meio do mecanismo chamado Price Specie Flow, mencionado por Harris, no século XVIII, e depois por Hume e Cantillon, era possível esperar que o país emissor, tendo preços mais elevados, e sob condiçôes de conversibilidade-ouro, fosse levado a importar mais. Isso levaria a vazamentos de ouro, drenando o excesso de moeda e garantindo não apenas o equilíbrio do balanço de pagamentos, mas também a distribuição equilibrada dos metais preciosos entre os países. Esse era, portanto, o argumento usado para justificar os déficits de balanço de pagamentos observados no período, atribuídos à suspensão da conversibilidade da moeda, que vigorou entre 1797 e 1821, apesar da vigência formal do padrão-ouro.

Os bulionistas moderados, como Thornton, chamavam a atenção para outras razóes para o prêmio do bullion (O’Brien, 2004), como era o caso de uma demanda extraordinária do metal, ou um balanço de pagamentos desfavorável 
por motivos independentes de emissão exagerada, exigindo mais pagamentos em bullion. Era também o caso da velocidade de circulação da moeda variando em função do estado de confiança. Nesses casos, não seria adequada uma contração monetária.

Essa era uma posição moderada com relação a Ricardo, que afirmava, ao contrário, a esse respeito:

Não tenho conhecimentos de causas outras que não o excesso ou o desejo de confiança nas emissöes de papéis (que, estou certo, não existem atualmente), que poderiam produzir tais efeitos que nós estamos testemunhando há muito tempo" (Ricardo, 1952, cf. Viner, 1937). ${ }^{3}$

Para os antibulionistas, como Torrens, ao contrário, o aumento dos preços não se devia a excesso de emissão ou de inconversibilidade da moeda, mas a outras causas, como a variação da velocidade de circulação dessa, em função de expectativas de depreciação do papelmoeda. Seus argumentos baseavam-se também na chamada Reals Bills Doctrine, segundo a qual as notas eram emitidas como pagamento de letras de câmbio que se baseavam ou eram lastreadas em bens reais, não havendo, portanto, excesso de emissão. Temiam, assim, uma contração monetária, porque percebiam que, se houvesse queda da velocidade de circulação por expectativa de apreciação monetária, a contração poderia ser maior do que a esperada, com efeitos catastróficos sobre a economia real.

Para Torrens (O'Brien, 2004), a oferta extra de moeda levaria a aumento da renda, e, enquanto houvesse desemprego a ser ocupado, surgiriam economias de escala na produçáo que compensariam o impacto inicial sobre os preços. Observe-se, já aqui implícito, da parte dos antibulionistas, o argumento de não neutralidade da moeda.

$\mathrm{O}$ argumento dos críticos antibulionistas não apenas explicita a dificuldade implicada no controle da dinâmica monetária (moeda endógena), mas o seu temor deixa clara a percepção dos impactos monetários sobre a economia real, ou seja, a não neutralidade da moeda. Essa não neutralidade era afirmada quando, mesmo concebendo o crescimento dos preços, viam os preços dos produtos crescendo antes daqueles dos fatores de produção, ou da renda nominal antes dos preços, ou ainda o aumento dos gastos antes do aumento dos preços. Tal entendimento permitia que justificassem aumento do emprego e da produção, impedindo que os aumentos do nível geral de preços fossem proporcionais aos aumentos de moeda ou crédito, conforme a TQM.
"I am not aware of any causes but excess, or a want of confidence in the issues of the paper (which I am sure does not now exist), which could produce such effects as we have for a considerable time witnessed". 
4 The rate of exchange is governed by the balance of payment operations, and (great political convulsions apart) by no other principle whatever...
Quanto aos déficits do balanço de pagamentos, os antibulionistas não consideravam que decorriam da inconversibilidade da moeda ou do excesso de emissão, mas atribuíam-nos a pesadas remessas militares do período, assim como a crescimento das importaçóes para compensar quebras de safras, razōes que requeriam o envio de bullion, justificando seu prêmio. Ou seja, o prêmio do bullion ou as trocas internacionais, sob suspensão da conversibilidade, como era o caso na maior parte do período dessa controvérsia, não dependiam de fatores internos, mas externos. Dizia Boase, por exemplo,

a taxa de câmbio é governada pelas operaçóes do balanço de pagamentos e (excetuadas grandes convulsóes politicas) por nenhum outro princípio (Viner, 1937, nota 59, capítulo III). ${ }^{4}$

Assim, neste debate temos, de um lado, os bulionistas, que pregavam a volta da conversibilidade-ouro da moeda como regra monetária para controle de emissão e preços, e, de outro, os antibulionistas, os quais temiam esse tipo de controle porque inibia o crescimento e a acumulação do capital.

Náo se trata de priorizar de forma absoluta, no primeiro caso, o controle de preços e, no segundo, o crescimento econômico, mas em relação ao espera- do pelos argumentos da TQM. Ou seja, no caso dos bulionistas, é a neutralidade da moeda que os faz náo esperar impacto duradouro da moeda ou do crédito sobre a produção real, levando-os a priorizar o controle de preços. Como é sabido, para Ricardo (1951), o crédito é mera transferência de poupança de poupadores para investidores, não implicando estímulo líquido para a produção.

No caso dos antibulionistas, o impacto sobre o emprego e a produção é temido, porque percebem a não neutralidade da moeda, e esse impacto sobre a produção faz com que, na igualdade de trocas, não se possa esperar crescimento proporcional dos preços. Mais que isso, se a moeda não é neutra, é possível esperar, pela equação de trocas, até algum impacto deflacionário.

Durante os anos em que durou a controvérsia entre bulionistas e antibulionistas, na maior parte do período (1797 e 1821), a conversibilidade-ouro esteve suspensa, e até 1814 houve inflação. Em 1810, iniciou-se uma depressão e depois um período longo de deflação, agravada com a volta da conversibilidade. Nesse período, os bulionistas perdem terreno e vários deles se colocam contra o padrão-ouro.

De fato, enquanto os bulionistas como Ricardo continuavam insistin- 
do nas teses anteriores, preocupando-se sobretudo com a estabilidade de preços, os impactos negativos dos limites impostos à expansão monetária sobre a produção real passam a aparecer nos argumentos dos antibulionistas. Ricardo atribuía a deflação de preços a erros do Banco da Inglaterra. Os antibulionistas, porém, desenvolviam argumentos mostrando que a deflação tinha efeitos adversos sobre o volume de riqueza e produção. Observe-se aqui que a queda da produção ocorre como resposta à queda dos preços. Assim, mesmo se os preços se alteram, não chegam a se alterar proporcionalmente ao excesso de emissão, na equação de trocas, porque afetam também a produção real.

Thomas Attwood, representante de grupo de pensadores ainda mais heterodoxo que os antibulionistas, ${ }^{5}$ dizia, por exemplo, que a queda de preços

primeiro de um artigo e depois de outro, sem correspondente queda nas dividas e obrigaçóes, tem o efeito de destruir toda confiança na propriedade, e todos os estímulos para sua produção, ou para qualquer forma de emprego de trabalhadores (1817, p. 78-78, cf. Viner, 1937, IV. 2). ${ }^{6,7}$

Outros argumentos atentam também para os impactos reais negativos que a moeda tem no período, negando a neutralidade dela. É o caso, por exemplo, quando consideram a contração monetária “injurious” (Viner, 1937, IV. 23), porque a rigidez de custos impede algumas produçóes de reduzir logo os preços. Também usam o argumento de poupança forçada para explicar o impacto positivo de uma expansão monetária. Mesmo que os preços subam, restringem consumo, aumentando a poupança, e o aumento de moeda retido por empresários os leva a investir mais, aumentando a produção.

Para Ricardo, porém, esse argumento náo era pertinente, uma vez que, para ele,

crédito [...], é o meio que é transferido alternadamente de um para outro, para usar o capital efetivamente existente; ele náo cria capital; ele determina somente por quem o capital pode

\footnotetext{
5 Thomas Attwood pertencia à chamada Birmingham School, cujos principais trabalhos, conforme Schumpeter (1994), apareceram entre 1815 e 1828 , ou seja, entre as controvérsias bulionistas $\mathrm{x}$ antibulionistas e Currency School x Banking School.

6 "First upon one article and then upon another, without any

upon debts and obligatons, it has the effect of destroying all confidence in property, and all inducements to its production, or to the employment of laborers in any way".

7 As referências a Viner (1937) vêm seguidas do capítulo e do parágrafo, uma vez que o livro foi obtido na internet e acha-se assim dividido.
} correspondent fall taking place 
8 Credit [...], is the means which is alternately transferred from one to another, to make use of capital actually existing; it does not create capital; it determines only by whom that capital should be employed [...]. ser utilizado (Lords Comitee, Report, 1819, p. 192-93, cf. Viner, 1937, IV. 40). ${ }^{8}$

Concluía dizendo que não acreditava em nenhum estímulo à produção resultante do uso do que chamava de "capital fictício".

$\mathrm{Na}$ segunda controvérsia, ocorrida entre 1825 e 1875, observa-se, logo de início, uma modificação com relação à primeira. Tanto o lado mais ortodoxo da Currency School quanto o lado mais heterodoxo da Banking School assumem a conversibilidade-ouro como a regra necessária, o que muito provavelmente se deve ao temor da inflação que vigorou durante a maior parte do período anterior às discussóes, sendo o ponto de divergência a necessidade de controles de curto prazo, além do oferecido a longo prazo pela conversibilidade-ouro. Nesse sentido, observa-se uma ortodoxização da discussão, conforme mencionado.

De fato, a Currency School vai pregar controles quantitativos de curto prazo, procurando fazer com que o sistema misto funcionasse como puramente metálico. Para isso, propunha, em primeiro lugar, o Currency Principle, segundo o qual a quantidade de moeda em circulação só poderia crescer quando houvesse entrada de ouro líquida no país, e cairia quando houvesse saída de ouro.
De forma complementar, a Palmer Rule requeria que o sistema bancário mantivesse o mesmo volume de título em reservas, de forma a garantir que a emissão de notas bancárias fosse lastreada em reservas de ouro em espécie. Finalmente, a lei bancária de 1844, que formalizou a transformação do Banco da Inglaterra em autoridade monetária, reconheceu a necessidade de centralizar o controle monetário separando os departamentos de emissão e bancário.

O principal objetivo de todas essas medidas era o de impedir flutuaçóes do nível de negócios resultantes de mudanças do nível de preços no curto prazo. Havia a percepçáo, por parte dos seus defensores, de que a mera conversibilidade-ouro levava certo tempo para corrigir problemas relativos ao excesso de emissão, e era preciso impedir que durante esse tempo houvesse flutuaçóes. Dizia a esse respeito Overstone (citado por O’Brien, 2004, p. 184), que:

Existe um antigo provérbio oriental que diz que você pode interromper com uma agulha uma fonte que, se continuar a correr, vai varrer cidades inteiras no seu curso. Uma contração rápida e em tempo hábil, a partir de uma primeira indicação de excesso na circulação, é a aplicação da agulha na fonte; convulsão comercial e ruina em conse- 
qüência do atraso são a corrente varrendo as cidades inteiras no seu curso. ${ }^{9}$

A Palmer Rule foi objeto de críticas dos próprios partidários da Currency School. A crítica relacionava-se com o fato de que, para manter a ideia do Currency Principle, era preciso garantir não apenas que os títulos permanecessem constantes, mas que os depósitos também não variassem. Esse tipo de crítica abriu uma discussão importante sobre os substitutos da moeda e a diferença de velocidade de circulação desses impondo dificuldades para o controle monetário por parte do Banco da Inglaterra, discussôes importantes no debate sobre a endogeneidade ou a exogeneidade da moeda.

A Banking School chamava a atenção que os depósitos e as letras de câmbio também fossem moedas, ou substitutos dela, e afetavam os preços. O controle de um tipo de moeda sem o controle do outro levava à fuga do controle pela substituição entre eles. Mesmo, portanto, com a separação dos departamentos de emis- são e bancário, poderia haver variação de depósitos e letras bancárias no próprio departamento bancário, fugindo do controle do departamento de emissão. Percebiam, assim, já nessa época, a influência das inovaçóes financeiras para fazer variar endogenamente a quantidade de meios de circulação. Além disso, levavam em conta a possibilidade de entesouramento ou desentesouramento, tornando o controle da quantidade de moeda inviável. ${ }^{10}$

Os participantes da Banking School não apresentavam sugestóes de controle porque consideravam, como banqueiros, que os bancos, por estarem próximos à demanda que refletia o ritmo de negócios, eram os melhores controladores. Mais que isso, acreditavam na real bills doctrine, ou, como também chamada, na lei do refluxo, pela qual os empréstimos concedidos, uma vez saldados, retornam ao sistema bancário, não havendo, por isso, excesso de moeda. Finalmente, diziam que, mesmo se hou-

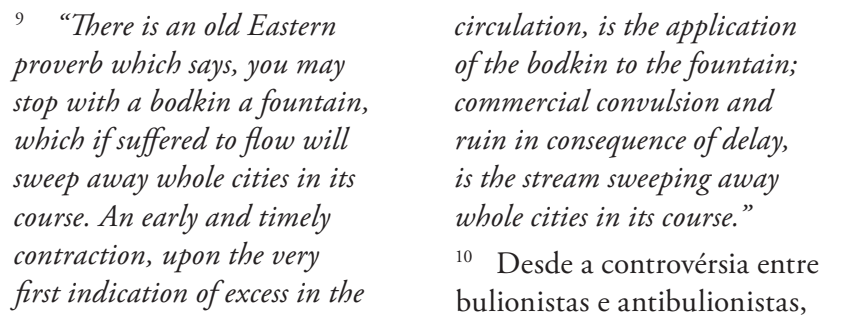

9 "There is an old Eastern proverb which says, you may sweep away whole cities in its contraction, upon the very first indication of excess in the já se punha a questão das dificuldades para o controle monetário. Sayers (1960), por exemplo, chama a atenção que Thornton, bulionista moderado, no seu Paper Credit, de 1802, dá mostras de que os countries banks eram substancialmente governados pelo Banco da Inglaterra, mas o relatório do Bullion Comittee de 1810, do qual participou, reconhece os limites de tal controle. 
vesse aumento de preços, não poderiam se desviar muito do nível de preços internacional, em função da perda de ouro com a conversibilidade estabelecida.

De novo a heterodoxia, agora representada pela Banking School, temia tais controles mais estritos, alegando que seriam inviáveis e indesejáveis, dando mostras, neste segundo caso, da percepção da não neutralidade da moeda. Por um lado, viam a quantidade de moeda dependendo do nível de preços, e não o inverso. Por outro, essa quantidade dependia do ritmo de negócios, uma vez que esse afetava a demanda de crédito aos bancos que, então, apenas a acomodavam. Esses fatores levavam à percepção da moeda como endógena, justificando a dificuldade para o seu controle. Além disso, nessas circunstâncias, a contração monetária poderia frear o ritmo de negócios, explicitando sua não neutralidade e a indesejabilidade do dito controle. Sustentavam, pois, que era preciso distinguir desequilíbrios de curto prazo relacionados ao ritmo de negócios - que exigiam uma política de crédito flexível para não abalar a confiança, e controles de longo prazo - para evitar o escoamento de ouro (Dean, 1980).

Além de considerar o controle monetário difícil, ou inviável, essa escola não via necessidade desse e apoiava sua argu- mentação na já mencionada lei do refluxo. Como bons banqueiros, justificavam o controle exercido pelos próprios bancos, competindo entre si, como o mais adequado, por eles estarem mais próximos dos negócios, percebendo-lhes o ritmo e, então, a necessidade de crédito. Um eventual excesso de notas seria ainda convertido em letras de câmbio e/ou troca delas por ouro para exportaçáo, e, portanto, drenado. Propunham, assim, que o controle último fosse feito pela conversibilidade-ouro, considerando as flutuaçôes nesse meio tempo normais, decorrentes do ritmo de negócios (banking principle).

A Banking School condenava os controles de curto prazo, não apenas por considerá-los inviáveis, como vimos, mas porque os considerava indesejáveis. Por um lado, poderiam aumentar as flutuaçóes. Quanto ao controle por meio da taxa de desconto, os oponentes do padrão metálico puro consideravam custoso porque, em situação de aumento dessa taxa e restrição ao crédito, podia se ter queda de crescimento. Dizia Tooke, expoente máximo da Banking School, que

[...] o efeito no intercâmbio de um aumento da taxa de juros seria o de induzir os capitalistas estrangeiros a se abster de retirar seus fundos do nosso país, na mesma magnitude que o fariam em outras circunstâncias, e isso operaria, ao 
mesmo tempo, diminuindo o estímulo dos capitalistas do nosso pais para investir em titulos estrangeiros, para poder fazer investimentos nas açóes e participaçôes britânicas [i.e., domésticas]. Isso teria também como conseqüência restringir o crédito de comerciantes nesse pais por meio de adiantamentos em carregamentos externos e teria o efeito de causar uma grande proporção de importaçóes para o país realizadas com capital estrangeiro (Tooke, 1840, p. 369, cf. Viner, 1937, capítulo V, nota 167). ${ }^{11}$.

Apesar de essa citação dar margem à interpretação segundo a qual poderia haver impacto de mudanças na dinâmica monetária sobre a economia real, ou seja, sobre a não neutralidade da moeda, a posição de Tooke e da Banking School, a esse respeito, parece ser mais enfática na endogeneidade da moeda do que na sua não neutralidade. Essa parece ser a razão para a percepção de Schumpeter de pouca divergência entre os pensamentos da Currency School, em particular, de Lord
Overstone, e de Tooke, como representante da Banking School, no que se refere aos ciclos de negócios. Lord Overstone, conforme Schumpeter (1954, p. 745), “explicitamente estabeleceu que não é a política dos bancos que produz ondas de crescimento". ${ }^{12}$ Ao contrário, para ele a moeda e o crédito desestabilizavam a economia em função do seu impacto inflacionário. Tooke, por sua vez, também segundo Schumpeter (1954, p. 746),

minimizou o papel da taxa de juros no ciclo; ele não pensou que a contração de crédito era o fator mais importante causando $o$ declinio. ${ }^{13,14}$

Schwartz (1989, p. 47), entretanto, menciona que tanto a Currency School quanto a Banking School atribuíam os ciclos econômicos a causas reais. Chama a atenção, porém, que Torrens, apesar de membro da Currency School, atribuía os ciclos de negócios a ações do Banco da Inglaterra, parecendo com isso recuperar seu passado antibulionista, e os re-

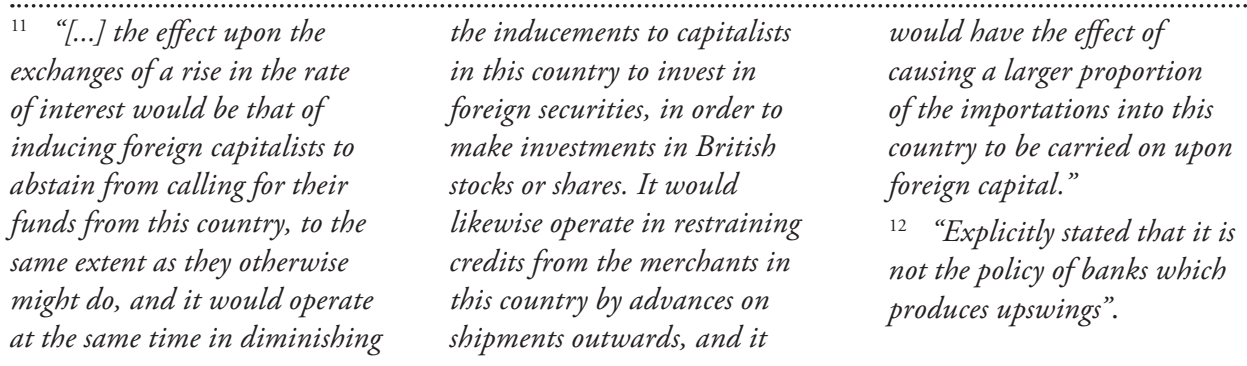

13 Ênfase no original.

14 "Minimized the role of interest in the cycle; he did not think that the contraction of credit was the most important factor in causing the downturn." 
15 "The guinea was made for man, and not man for the guinea".

16 "Whenever [...] the money of a country is sufficient to call every laborer into action, upon the system and trade best suited to his habits and his powers, the benefits of an increased circulation can go no farther". presentantes da Banking School imputavam também a fatores monetários "tanto a origem quanto a dimensáo dos ciclos de negócios".

O pensamento mais efetivamente heterodoxo, ao longo de todo o período em que duraram as duas controvérsias, tanto entre a Currency School a Banking School, quanto entre bulionistas e antibulionistas, era o de Thomas Attwood, da Birmingham School. Os adeptos desta escola se mostraram contrários ao automatismo do padrão-ouro, por considerar que trazia consequências danosas para o crescimento e o emprego. Dizia Attwood (1817, p. 95, cf. Viner, 1937, IV.0), que "o guinéu foi feito para o homem e não o homem para o guinéu", ${ }^{15}$ mostrando como as impulsóes monetárias poderiam levar ao pleno emprego. Mais explicitamente ainda, dizia que

sempre que [...] o dinheiro de um pais seja suficiente para colocar todo trabalhador em ação, no sistema e comércio mais apropriados aos seus hábitos e poderes, os benefícios de uma circulaçâo aumentada podem ser ampliados (p. 68). ${ }^{16}$

Mas entendia que, a partir desse ponto, qualquer estímulo adicional seria vão ("nugatory") e injurioso ou prejudicial (“injurous") (Viner, 1937, citando Attwood, cap. IV, nota 118). Daí a posi- ção contrária da escola ao padrão-ouro e, mais ainda, à reforma bancária que transformava o sistema misto em metálico.

Conforme destaca Dean (1980, p. 83), a dominação ortodoxa e dos seus princípios só durou tanto na Inglaterra do século XIX em função da posição hegemônica dela, que lhe conferia confortáveis superávits. Assim, "limitaçôes automáticas sobre a política de crédito interno só raramente foram muito exigidas". Tal não é o caso do Brasil, como veremos no próximo item, que enfrentava, como outros países menos desenvolvidos, problemas e sacrifícios relacionados às exigências de reservas durante o padrãoouro. Os problemas enfrentados pelo país vão explicitar, de outra maneira, a não neutralidade da moeda. Daí a absorção pelos desenvolvimentistas das teses críticas dos heterodoxos, chamados no Brasil de "papelistas", ideias que analisaremos no próximo item.

Antes, contudo, e para finalizar as ideias discutidas no século XIX, é preciso destacar uma observação crítica à análise realizada por Schumpeter (1954) sobre a posição de Marx a respeito dessas controvérsias. Apesar de trabalhar com a teoria do valor-trabalho, como Ricardo, e de considerar que, na esfera internacional, a moeda teria sempre que ser o ouro, como explicita no Livro I de $\mathrm{O} \mathrm{Ca}$ - 
pital, Marx possui uma posição sobre a moeda e o crédito muito distante da dos bulionistas, em particular quando se trata, como é o caso neste artigo, de perceber os efeitos da moeda e do crédito sobre a economia real, potencializando a acumulação de capital. Assim, parecenos que não cabe, como faz Schumpeter, associá-lo aos bulionistas.

Nesse sentido Marx mostrou-se até particularmente crítico das ideias monetárias da Currency School, em particular no que se refere aos controles de curto prazo por eles propostos. A esse respeito, diz Marx (1974, p. 635) que "[...] nas províncias, a suspensão a lei bancária teve o efeito de medida salvadora”, mostrando, assim, que percebia o caráter contracionista e discutível das restriçóes da lei bancária de 1844. Aliás, mais de uma vez colocou-se a esse respeito do lado da Banking School, embora discordasse das definiçóes de capital de Tooke e de que os bancos eram os melhores controladores do meio circulante.

Mais que isso, há referências explícitas de Marx (1971, p. 642-643) à Birmingham School, mostrando exatamente o lado perigoso das medidas de contenção monetária. Diz ele a esse respeito:

Ouçamos agora um banqueiro particular, Twell, desde 1801 sócio de Spooner,
Attwoods \& Co. Entre todas as testemunhas perante a Comissäo Bancária (B. C. ) de 1857, é a única que penetra na situação real do país e vê a crise aproximar-se [...]

Declara ele: 4488: Quais foram a seu ver, os resultados da lei de 1844? - Se the respondesse como banqueiro, diria que foram magnificos, pois proporcionaram colheitas abundantes aos banqueiros e aos capitalistas [financeiros] de toda a espécie. Mas, foram muito ruins para o homem de negócios honrado e ativo, que precisa de taxa estável de desconto para transacionar com segurança. [...] A lei tornou o empréstimo de dinheiro negócio altamente lucrativo.

4490: Pequenos negociantes e comerciantes respeitáveis que não têm grande capital [...] muito os aperta a lei [...] $O$ único meio que tenho para saber disso é a massa surpreendente de aceites que vejo não serem pagos. Esses aceites correspondem a quantias pequenas [...], e muitos deles não sã pagos, retornando sem resgate em todas as circunscriçôes do país [...]'.

Constata-se, desta forma, que, mesmo quando discorda de Tooke, Marx o faz de modo ainda mais heterodoxo. Defende, por exemplo, que a circulação de bilhetes 
é independente náo só da vontade do Banco da Inglaterra, mas também do nivel do encaixe em ouro guardado nas casas-fortes do Banco e que garante a conversibilidade desses bilhetes (Marx, 1971, p. 603).

Com isso, reforça ainda mais o papel da demanda ou do ciclo de negócios como fator de pressão do aumento da oferta de empréstimos (Mollo, 1994), e nega, com isso, que os bancos pudessem ser os melhores controladores, como afirmava a Banking School.

\section{3_Metalistas e papelistas no Brasil}

Quanto ao debate no Brasil, sua singularidade deve-se, em primeiro lugar, ao fato de se circunscrever ao contexto de uma economia fundamentalmente agroexportadora. Todavia, assume também caráter peculiar por centrar-se na discussão sobre o modus faciendi da política econômica, em suas prioridades e operacionalização, ao incorporar novo foco ao debate econômico, tradicionalmente centrado na antiga polaridade entre liberalismo e intervencionismo. Enquanto essa se centrava nas razóes sobre se o Estado poderia ou não intervir na economia, recorrendo a argumentos doutrinários ou axiológicos, coerentes com a formação jurídica dos bacharéis e homens cultos da época, a contenda entre papelistas e metalistas rompia em algo à primeira vista mais simples, mas responsável por profundas consequências na operacionalização da política econômica e no manejo de seus instrumentos. Passava-se a enfatizar, em um tom mais pragmático, já que visava à utilização imediata, quais deveriam ser os objetivos de curto prazo da política econômica e a melhor combinação de instrumentos e meios para viabilizá-los.

A discussão entre papelistas e metalistas tinha como epicentro a conversibilidade da moeda, algo essencial em uma economia voltada à agroexportação, como a brasileira, no período das últimas décadas do Império às primeiras décadas da República. Remetia, por conseguinte, às políticas monetária e cambial, bem como à relação entre ambas. Os metalistas defendiam ferrenhamente o padrão-ouro e a conversibilidade da moeda; para tanto, encontravam respaldo na teoria econômica convencional e na política do país hegemônico, a Grã-Bretanha. Já os papelistas, ante a ausência de um corpo teórico de mesma envergadura para defender o desapego ao que consideravam amarras às políticas monetárias e cambiais, recorriam à razão prática: a experiência, e não uma teoria, demonstrava qual o melhor caminho a seguir. Devia-se isso em parte 
às dificuldades de manter o padrão-ouro e à plena conversibilidade no país. Como afirma Prado (2003, p. 97):

A tentativa continua de estabelecer uma moeda conversivel, sustentada em uma firme reserva de ouro, em uma sociedade periférica e pouco monetizada não era apenas impossivel de ser obtida, mas reduzia enormemente as oportunidades de investimento produtivo.

As críticas à conversibilidade eram comuns nos círculos produtores, seja da lavoura, inclusive escravista, seja no setor urbano, como o do comércio e o da indústria. $\mathrm{Na}$ ausência de estudos empíricos mais conclusivos para delinear que segmentos sociais defendiam uma e outra corrente, é de se supor que os rentistas, tendencialmente mais temerosos com a inflação, deveriam alinhar-se aos metalistas. Entre estes últimos devem-se citar Francisco Belizário, Torres Homem e Joaquim Murtinho, ministro da Fazenda de Campos Sales (1898-1902).

Schumpeter (1954, p. 407), ao arrolar os segmentos sociais alinhados a uma e a outra corrente no contexto inglês, ensaia uma interpretação:

Os politicos eram razoáveis - os arautos dos interesses agrários foram o único grupo que, como tal, chegou a pontos absurdos neste sentido [culpar a con- versibilidade como responsável pelas depressöes]. Todavia, os banqueiros, os financistas e os economistas inspirados pelos pontos de vista dos banqueiros e financistas, especialmente aqueles que se puseram na defensiva devido a sua defesa prévia do Bullion Report, em sua maioria, não tinham dúvida, apesar daquilo, que a raiz de todo mal era a moeda e nada mais [...].

Essa posição, porém, precisa ser relativizada, à luz da controvérsia mencionada na seção anterior entre a Currency e a Banking School. Como vimos, a Banking School, apesar de ter amplo trânsito entre os banqueiros, defendia a conversibilidade-ouro da moeda, mas temia regras que, controlando a quantidade de moeda, pusessem em risco o ritmo dos negócios.

O mesmo parece ocorrer no Brasil, conforme relato de Muller (2004, p. 32):

A história dos bancos no Rio de Janeiro durante o Império reflete as oscilaçóes do desejo do governo Imperial de deter o monopólio das emissóes e manter o padräo-ouro e dos bancos particulares que, via de regra, preferiam a pluralidade emissora e menos rigidez em relação ao lastro metálico.

Já Neuhaus (1975, p. 29), tendo em vista o Brasil no período em que o debate floresceu, pondera: 
A ortodoxia era tipicamente defendida por grupos urbanos assalariados (incluindo funcionários públicos, profissionais liberais, intelectuais, etc.) e por comerciantes importadores. Grandes consumidores ou negociadores de artigos importados, eles defendiam, naturalmente, a revalorização cambial. Em sua maioria recebiam salários relativamente fixos em termos nominais e que se ajustavam gradativamente às mudanças do indice de preços.

Ao se investigar com mais acuidade o pensamento dos papelistas, podemse detectar pelo menos dois grupos - semelhante aos "meios-termos" apontados por Schumpeter no contexto inglês. $\mathrm{O}$ primeiro, mais moderado, não negava a conversibilidade como regra, mas advogava seja seu relaxamento (como nas crises ou nas safras, para possibilitar aumento do meio circulante e "estímulo aos negócios"), seja uma ancoragem ao ouro mais flexível, como uma porcentagem de lastro que poderia ser alterada dentro de certos limites. Entre eles, podem-se citar Souza Franco (ministro na década de 1850), o barão de Mauá, os viscondes de Cruzeiro e de Ouro Preto, Joáo Alfredo e o conselheiro Laffayette. Já o segundo grupo, o qual tudo sugere congregar menor número de adeptos, inclui homens de perfil mais radical, como
Rui Barbosa, que, em alguns momentos, chegaram a negar e a entender como perniciosa qualquer regra de conversibilidade e a defender a pluralidade de bancos emissores e plena liberdade de atuação para que esses pudessem contra-arrestar os "ciclos dos negócios".

Cabe notar que esses principais representantes do papelismo, assim como os do metalismo, com quem mantêm a controvérsia, apareceram no Brasil, na segunda metade do século XIX -, portanto, com certa defasagem temporal com relação ao debate inglês, o qual, conforme mencionado, aflorara já com força no início desse século (1797-1825). Todavia, é razoável supor que os tenha inspirado, dada a hegemonia britânica à época não só econômica, mas também intelectual, principalmente em matérias atinentes à economia e finanças. Além disso, por ocasião do início do debate brasileiro, já havia se iniciado a controvérsia entre a Currency School e a Banking School (1825-1975), que, como vimos, apresentava alguma continuidade de ideias e divergências entre ortodoxos e heterodoxos, que também devem ter inspirado o debate brasileiro.

Retomando as linhas principais do debate: para os metalistas, a prioridade da política econômica era a estabilidade e a política cambial - e, por con- 
seguinte, a definição da taxa de câmbio tornava-se variável prioritária. Defensores do padrão ouro estabeleciam a relação entre política monetária e balanço de pagamentos: metais preciosos ingressariam naturalmente no país se a economia fosse saudável, e qualquer oferta de moeda sem lastro causaria inflação.

Observe-se aqui que, tal com para os bulionistas ingleses, os problemas tinham causa interna, o descontrole monetário, que precisaria ser contido pela regra constituída pelo padrão-ouro. A política monetária deveria ser subordinada, então, à política cambial, porque esta última imporia a disciplina monetária necessária para o controle dos preços. A liberalização dos mercados, tal como para os bulionistas e a Currency School, garantiria o ajuste do nível de divisas e a igualdade dos preços internos e externos.

Via de regra, os metalistas apoiavam-se nos grandes mestres da economia clássica, como Smith, Ricardo e Say. A taxa de juros era entendida como fenômeno real, à la Ricardo, dependente da taxa de lucro. Maior oferta de moeda não alterava o nível de atividade; como afirmava Francisco Belizário (Franco, 1983, p. 104), querer "prevenir as crises" através da queda da taxa de juros resultante de maior oferta de moeda era um equívoco, pois consistia em "confundir moe- da com capital" ao esperar-se que o aumento do estoque da primeira iria tornar o capital "mais barato, abundante e ao alcance de todos". Sendo a política monetária ineficaz, restava aumentar as condiçóes de competitividade real do setor exportador, garantir as regras de finanças sadias e manter uma taxa de câmbio realista para que a economia prosperasse.

Já a preocupação maior dos papelistas, dos mais moderados aos mais radicais, era com o nível de atividade econômica. Sua pergunta mais frequente, qual o nível de oferta monetária mais condizente com o ânimo dos negócios, consistia verdadeira heresia para os metalistas. Mauá, um de seus primeiros defensores, defendia o que se convencionou denominar "requisito da elasticidade": a oferta de moeda deveria ser flexível ou elástica a ponto de não interferir negativamente nas atividades produtivas. Menos teóricos e mais pragmáticos, apresentavam-se como coerentes com o bom senso: simplesmente o governo deveria ajudar, e não prejudicar a economia.

Segundo Franco (1983, p. 56), essas ideias, principalmente a partir da década de 1880, eram

antes considerada(s) uma expressáo dos 'interesses do comércio', do que uma posição legitimada pela autoridade de uma doutrina. 
Náo se pode esquecer de que os principais argumentos em favor do metalismo e dos principais esteios de sua política econômica - padrão ouro, livre cambismo e vantagens comparativas no comércio internacional - estavam consolidadas no pensamento clássico e possuíam elaboração teórica muito mais profunda e sofisticada, pelo menos desde Ricardo - embora fossem inegáveis as dificuldades práticas para implementálas, fato que variava de país para país. Por isso Mauá, em $O$ meio circulante do Brasil, de 1878 , em posição semelhante à de alguns membros da Escola Histórica Alemã, chegou a duvidar da universalidade das leis econômicas, ao ponderar:

[...] antes que uma teoria consiga firmar-se na sólida base da ciência, tem de pôr à prova as suas conclusóes, que devem ser invariáveis em todos os países e em qualquer ocasiáo.

A seguir, explicita a crítica à ortodoxia tendo por base as diferentes formaçóes históricas dos países - argumento que surpreende tanto por certa coloração "nacionalista" (característica que fará parte da retórica desenvolvimentista, como se mostrará adiante) como por praticamente coincidir, em sua tese central, com princípio caro ao pensamento desenvolvimentista do século XX, verbia gratia, o dos economistas cepalinos, como Prebisch e Celso Furtado.

$E$, na verdade, cumpre estar prevenido contra certas idéias apregoadas com dogmática severidade por parte de doutrinários inflexiveis, as quais nem sempre são aplicáveis a países onde as causas que determinam certos fenômenos sâo diversas, e, portanto, o regime aconselhado como salvador de altos interesses, para uns daria em resultado ficarem estes seriamente comprometidos em outros, se o bom senso nacional não repelisse o presente grego, que os chamados mestres da ciência lhe querem impor (Mauá, 1998, p. 282-283; grifos do autor).

A pesquisa empírica sobre alguns dos mais destacados participantes do debate brasileiro permite detectar algo que não foge ao padrão verificado internacionalmente: era frequente o aparecimento de defensores do afrouxamento das regras, em nome do pragmatismo, conquanto náo propusessem romper com o paradigma mais amplo. Gremaud (1997) argumenta na mesma direção, embora com foco na prática efetiva da política econômica, ao apontar fenômeno que se poderia considerar semelhante aos "meios-termos" de Schumpeter, e os associa a possibilidades variadas de combinaçôes institucionais no âmbito de um mesmo regime cambial, as quais possibilitam 
"nuanças relativas" diante dos impactos decorrentes das "oscilaçôes externas":

As opçôes regime cambial fixo $x$ flexivel, ou padrão monetário conversivel $x$ inconversivel, apesar de se constituirem na dicotomia básica nas controvérsias monetárias brasileiras do periodo e de evidenciarem as questóes relevantes dentro de uma economia não autárquica, escondem a possibilidade de formas intermediárias de gestão das questóes monetárias e cambiais e, especialmente, a ampla gama de mecanismos institucionais disponiveis dentro dos próprios extremos da dicotomia (Gremaud, 1997, p. 5).

Para os papelistas, a atenção maior da política econômica deveria estar na taxa de juros, e não na taxa de câmbio. Embora ainda não houvesse um corpo teórico sólido que embasasse suas teses, não há dúvida de que essas eram instigantes e se aproximam, em alguns aspectos, do futuro keynesianismo, além de não possuírem grau de sofisticação menor do que as dos metalistas. A taxa de juros refletia o estado de ânimo da economia e era um fenômeno estritamente monetário, determinada por oferta e demanda de moeda. Não haveria relação entre as variações da política monetária e o câmbio, e argumentava-se que a velocidade de circulação da moeda em um país como o Brasil era baixa, em razão de ser um país agrícola, de significativa extensão territorial e alta propensáo a entesourar.

O crescimento tornava-se a variável central da economia e, para isso, a política cambial, ao contrário do proposto pelos metalistas, deveria subordinar-se à política monetária, e esta às necessidades impostas pela produção. Nesse sentido, assim se manifestou o conselheiro Afonso Celso em 1879: "A circulação fiduciária não influi, nesta praça, para a queda do câmbio" (Barbosa, 2005, p. 96). E Lafayette, em sessão do Senado de 26 de junho de 1888:

Não é o papel-moeda que diminui o preço [do câmbio], é o ouro que sobe, como mercadoria rara no Brasil. Se há, portanto, só raridade do ouro, não procede o argumento da depreciação da moeda (p. 98).

E, finalmente, vale transcrever o tom enfático de Rui Barbosa:

Não é a circulação monetária que nos há de firmar o câmbio alto; é, pelo contrário, a estabilidade no câmbio ao par, efeito da prosperidade econômica da nação, que nos há de permitir a circulaçâa conversivel. Os metalistas invertem os termos do problema, e por isso as suas criaçóes não passam de cas- 
telo de cartas. Os saldos a favor do pais, nas liquidaçōes internacionais, geram o câmbio favorável; o câmbio duradouramente favorável determina a circulação metálica. Nós, ao revés, queremos, pela circulaçấo metálica artificialmente preparada, fazer o câmbio, apoiando-a em saldos transitórios promovidos por empréstimos externos. É uma pretensão puerilissima (Barbosa, 2005, p. 59).

Observe-se aqui que há claramente nesses argumentos a ideia [melhor: a defesa do uso] de uso aconselhável da política monetária para impulsionar a atividade econômica, em vez de priorizarem a disciplina monetária para controle de preços. Assim, a conversibilidade era vista como uma medida artificial, prejudicial ao ânimo dos negócios; o câmbio alto não deveria ser buscado por uma conversibilidade artificial, mas pela prosperidade da nação. Daí decorria que as dificuldades do balanço de pagamentos não deveriam ser enfrentadas com medidas restritivas, mas com mais crescimento. Esse argumento tornar-se-á mais tarde uma das teses centrais do desenvolvimentismo e da heterodoxia teórica.

Essa posição flexível dos papelistas foi praticada por Rui Barbosa nos primeiros anos da República. A tentativa de resolver as crises via emissão monetária fora implementada em outras conjunturas do
Império, como, em seu final, na reforma monetária de 1888. Mas com Rui a medida foi levada às últimas consequências ao permitir o direito de emissão aos bancos privados, claramente se entendendo que o estoque monetário é que deveria se adequar às necessidades da produção, ou seja, às necessidades domésticas da demanda por transaçóes.

Dessa concepção, decorria a questão já mencionada: como saber qual o nível de estoque monetário desejável para manter o crescimento da economia? Dado que a inflação não era vista como a única consequência monetária, e, por isso, não era o problema principal, a resposta era: acompanhando-se o nível de investimento, já que esse dependia da taxa de juros e era o melhor sintoma do ânimo da economia. Por isso, defendia Rui Barbosa que era a taxa de juros, e não a taxa de câmbio, a variável-chave da economia, e que aquela deveria ser manipulada sem as amarras do padrão-ouro, para fomentar a "circulação de riqueza”. E completa:

O barômetro das exageraçóes do meio circulante não é a taxa de câmbio, que pode oscilar sob a ação de outras influências: é a taxa de juros. Baixa o juro quando superabunda a moeda corrente; sobe quando ela enrarece (Barbosa, 2005, p. 150). 
O papelismo, desta forma, representou uma precoce heterodoxia ao redefinir quem era o cão e quem era a cauda, para lembrar a metáfora dos keynesianos da década de $1930,{ }^{17}$ e, com isso, priorizar o investimento sobre a poupança, a taxa de juros sobre a taxa de câmbio e o crescimento sobre a estabilidade.

\section{4_A origem papelista do desenvolvimentismo e a não neutralidade da moeda}

Vimos, na primeira parte deste trabalho, que as controvérsias monetárias do século XIX, na Inglaterra, centram-se sobre questóes ligadas à aceitação ou não da TQM. Esta teoria, sabemos, implica alguns pressupostos que, uma vez aceitos, levam a resultados, do ponto de vista teórico, que conduzem necessariamente a prescriçóes distintas.

Partindo da equação de trocas $\mathrm{MV}=\mathrm{Py}$, mera igualdade contábil, sobre a qual todos concordam inicialmente (Aftalion; Poncet, 1984), são os argumentos de exogeneidade e neutralidade da moeda que garantem a aceitação da TQM. Isso porque é o suposto de entesouramento irracional que permite falar de velocidade de circulação constante, estável ou previsível, e é o suposto de pleno emprego dos fatores de produçáo que não pode ser afetado de forma duradoura por impulsóes monetárias (aumento de moeda ou crédito) que garante o aumento proporcional do nível de preços respondendo a elas.

A prioridade ao controle dos preços decorre da aceitação da TQM, assim como a percepção de que qualquer efeito sobre a produção real é no máximo transitório, e, enquanto isso, o crescimento do nível geral de preços leva a distorçóes nos preços relativos, devendo ser evitado. Mais que isso, qualquer restrição ao crescimento dos meios de circulação ou do crédito não é vista como muito problemática, justamente porque a moeda é concebida como neutra a curto ou a longo prazos. ${ }^{18}$

\begin{tabular}{|c|c|}
\hline 17 A metáfora refere-se à & normalmente em termos \\
\hline relação de causalidade entre & de um modelo de realidade \\
\hline poupança de investimento, & no qual um cão chamado \\
\hline lembrando que, para & poupança maneia sua cauda \\
\hline Keynes, o investimento é que & chamada investimento, para \\
\hline impulsiona a poupança, por & os termos de modelo, no qual \\
\hline meio de sua determinação no & um cão chamado investimento \\
\hline nível de renda, contrariando a & maneia sua cauda chamada \\
\hline lógica clássica que enfatizava & poupança" (in: Keynes, 1977, \\
\hline $\begin{array}{l}\text { o papel da p } \\
\text { haver investi }\end{array}$ & 18 Para uma discussão da \\
\hline Meade: "A revoluçấo & questáo neutralidade da \\
\hline intelectual de Keynes & moeda entre a ortodoxia e a \\
\hline consistiu no deslocamento do & heterodoxia monetárias, ver \\
\hline pensamento dos economistas, & Mollo (2004). \\
\hline
\end{tabular}

${ }^{17}$ A metáfora refere-se à relação de causalidade entre poupança de investimento, lembrando que, para

Keynes, o investimento é que por meio de sua determinaçáo no haver investimento. Segundo consistiu no deslocamento do de um modelo de realidade no qual um cão chamado poupança maneia sua cauda chamada investimento, para um cão chamado investiment maneia sua cauda chamada poupança" (in: Keynes, 1977 . 54; grifos do autor)

8 Para uma discussão da Mollo (2004). 
É, ao contrário, a percepção da náo neutralidade da moeda - com o decorrente impacto que a moeda pode ter sobre a produção real, por meio de economias de escala ou do crescimento de preços antes dos custos ou ainda das rendas antes dos preços, podendo levar a aumentos de produção e emprego - que permite os antibulionistas defenderem que o nível geral de preços não cresça proporcionalmente à quantidade de moeda. Assim, a prioridade deixa de ser o controle de preços e passa a ser o crescimento do emprego, passível de ser estimulado por impulsões monetárias. É justamente a percepção da não neutralidade da moeda, na prática, com os efeitos catastróficos observados quando da retomada da conversibilidade da moeda, que ensejou vários bulionistas a reverem suas ideias, ou perderem o entusiasmo pela volta ao regime metálico (Viner, 1937).

Esse tipo de preocupação é que justifica a relação entre os papelistas e os desenvolvimentistas, no caso do Brasil. Como o nome diz por si mesmo, a prioridade era o crescimento, que se mostrara comprometido, no Brasil, em diferentes momentos, pelo padrão-ouro. $\mathrm{O}$ padrão-ouro reduzia as oportunidades de investimento, conforme mencionado na referência anterior a Caio Prado Jr. Furtado (1977), que analisa as dificul- dades impostas pelo padrão-ouro para o equilíbrio do balanço de pagamentos. Segundo ele, uma economia exportadora de produtos primários sofre com a queda maior e mais duradoura nos preços de suas exportaçóes em comparaçáo com sua demanda de importaçóes, ocasionando uma perda nas relaçóes de intercâmbio, a qual se acentua, no mesmo contexto, com a redução da entrada de capitais. Assim, o sistema de padrão-ouro não traria o benefício do "ajuste automático" propalado por seus defensores:

Em tais condiçôes, é fácil prever as imensas reservas metálicas que exigiria o pleno funcionamento do padräoouro numa economia como a do apogeu do café no Brasil. À medida que a economia escravista-exportadora era substituida por um novo sistema, com base no trabalho assalariado, tornavase mais difícil o funcionamento do padräo-ouro (Furtado, 1977, p. 159).

Para mostrar a influência do papelismo no desenvolvimentismo brasileiro, tomaremos como caso a trajetória de Vargas - já que este foi o personagem central do Estado desenvolvimentista, que marcou a experiência histórica brasileira após 1930. Em adição, como nosso propósito é resgatar as origens dessa influência, nossa opção metodológica consistiu em recuar às décadas anteriores a esse ano para recu- 
perar a referida gênese. No caso de Vargas, essa diz respeito à transição entre uma ideologia marcadamente influenciada pelo positivismo de Comte para, gradualmente, ao que mais tarde se chamou "desenvolvimentismo" - o qual, para a Bielschowsky (1988, p. 7), pode ser definido como a "ideologia de transformação da sociedade" assentada em um projeto econômico voltado à industrialização como via de superação da pobreza e do subdesenvolvimento da América Latina, sob o entendimento de que esta não adviria pela espontaneidade das forças de mercado, ou seja, seria indispensável à atuação do estado como indutor, agente planejador do desenvolvimento e/ou investidor direto.

Na mesma direção, Fonseca (2004, p. 226) defendeu que, enquanto a definição de desenvolvimentismo varie entre autores, há um "núcleo duro" para o qual há convergência entre eles, e que aponta para uma política econômica marcada pela defesa: (a) do nacionalismo, embora este deva ser entendido num sentido muito amplo, que vai desde a simples retórica ufanista conservadora até propostas radicais de rompimento unilateral com o capital estrangeiro); (b) da industrialização; e (c) do "intervencionismo pró-crescimento”, este entendido como a adoção de políticas monetárias, cambiais e fiscais para acelerar o crescimento econômico. A influência aqui abordada diz respeito, portanto, a esta última, posto que justamente nossa hipótese é que o "intervencionismo pró-crescimento", no caso brasileiro, tem suas origens nas teses papelistas.

Para se avaliar a importância do papelismo e do significado de sua heterodoxia, ao desviar-se do pensamento entâo dominante, deve-se lembrar o ambiente intelectual no qual as mesmas afloraram: da última metade do século XIX às primeiras décadas do século XX, com a inexistência de cursos de Economia, essa era uma disciplina das faculdades de Direito. Nessas, a polaridade do debate era entre os jusnaturalistas, de um lado, e os positivistas, de outro. Os primeiros, consonantes com a doutrina do liberalismo clássico, do direito natural e do contratualismo político herdado de Locke; em temas econômicos, defendiam o direito de propriedade como natural (inclusive o da propriedade de escravos, no Império), o laissez-faire e as regras de "finanças sadias" - equilíbrio fiscal e do balanço de pagamentos, bem como o padráo-ouro.

Já os positivistas seguiam certos conselhos de Comte sobre a melhor forma de administrar o Estado. Pretendendo desapegar-se dos dogmas liberais em favor de "princípios científicos", como 
bom positivista, Comte admitia a intervenção do Estado quando houvesse "necessidade social”, mas na prática essa era limitada por entender que o Estado, como "cérebro da sociedade", em uma analogia com biologia, deveria dar exemplo à sociedade: as regras do bom governante eram as mesmas da economia doméstica, ou seja, manter orçamento equilibrado, ser parcimonioso e evitar o endividamento. Assim, acabavam aceitando, ainda que sob argumentação diferente, as mesmas regras ortodoxas dos jusnaturalistas para a condução da política econômica (Fonseca, 2008).

A formação intelectual de Vargas deu-se nesse contexto. Perfilhou-se ao positivismo - então ideologia oficial do Partido Republicano Rio-Grandense (PRR), cujo maior teórico fora Júlio de Castilhos. Todavia, desde cedo, mostrou certo ecletismo ao mesclar as regras comtianas com ideias à época mais arrojadas, a sugerir certo desapego à ortodoxia positivista. Um dos primeiros discursos seus remonta ainda à época de estudante, em 1906, quando saudou o recém-eleito presidente Afonso Pena, que visitava o Rio Grande do Sul, em nome dos acadêmicos de Direito, do qual há o registro:

Quantas causas de estagnação pesam sobre um pais novo, exaurido pela captação e pelo fisco, sopeando o livre desenvolvimento das atividades industriais! Amarga resultante para quem se vê coato a comprar, manufaturados no estrangeiro, os gêneros da própria matéria-prima que exporta (Correio do Povo, 16/8/1906, p. 1).

A análise do discurso ressalta, já à primeira vista, que esse se assenta em várias antinomias, as quais possuem o inegável efeito discursivo de demarcar campo e polarizar o debate: estagnação/ desenvolvimento; manufaturas industriais/matérias-primas agrárias; nacional/estrangeiro; e país "novo" agrário/países exportadores de produtos industriais. Ora, parece inegável a semelhança entre essas ideias e as do futuro desenvolvimentismo, mesmo na sua forma mais acabada, consubstanciada nas teses cepalinas das décadas de 1950 e 1960: uma divisão internacional do trabalho perversa aos países periféricos, especializados na exportação de produtos primários, os quais tendencialmente perdiam nas relaçôes de intercâmbio com os países industriais dos centros hegemônicos.

De forma embrionária, já temos os três elementos do "núcleo duro antes mencionado": o afâ de falar em nome da nação, a sugerir um "interesse nacional"; a defesa da industrialização como alternativa; e, finalmente, o apelo ao presidente da República que tomasse me- 
didas para a reversão do quadro, ou seja, subjaz à manifestação o entendimento de que caberia responsabilidade ao Estado na reversão do quadro e na construção de outra opção para o país. Essa proposição sugere um tipo de intervenção estatal além da admitida pelo positivismo, uma vez que não se trata apenas de intervir para enfrentar um problema social emergente, mas aponta para uma noção de práxis - uma ação consciente, racional, voltada a um objetivo desejado de maior envergadura (e que mais tarde a tradição desenvolvimentista latinoamericana consagrou nas teses cepalinas como "transformação estrutural"). Enquanto o positivismo apregoava o "progresso dentro da ordem", agora se sugeria a necessidade de uma nova ordem para se chegar ao progresso, ou seja, ao desenvolvimento.

Da mesma forma, quando deputado estadual, em 1919, ao responder às críticas de outro deputado, Gaspar Saldanha, para quem o governo gaúcho era excessivamente interventor e prejudicial às atividades da pecuária e das charqueadas, contrariando a especialização "natural" decorrente das vantagens comparativas, Vargas argumentou:

[...] permita-me dizer que V. Exa. está filiado à velha teoria econômica do 'laissez-faire', teoria essa que pretende atribuir unicamente à iniciativa particular o desenvolvimento econômico industrial de qualquer país, deixando de lado a teoria da nacionalização desses serviços por parte da administração pública, amplamente justificada pelas liçóes da experiência, não levando $V$. Exa., em linha de conta, que nos paises novos, como o nosso, onde a iniciativa é escassa e os capitães ainda não tomaram o incremento preciso, a intervenção do governo em tais serviços é uma necessidade real (Annais da Assemblea ..., 1919, p. 124-127).

Prosseguindo, Vargas argumentou que na Europa a intervenção estatal, "açambarcando a atividade particular, monopolizando serviços, etc. deu os melhores, os mais surpreendentes resultados". Para Saldanha, entretanto, tal intervencionismo ocorrera em caráter excepcional, em um contexto de guerra, o que permitiu Vargas contra-argumentar:

Tanto não é assim que após a terminação da guerra, os poderes públicos continuaram intervindo na atividade privada, mantendo-se esses serviços com o intuito de restringir a excessiva ganância dos particulares. E uma prova de eficácia e oportunidade dessas intervençôes está na tendência, quase generalizada na Europa, do operariado para a nacionalização das indústrias. 
É em face desta situação que S. Exa. vem colocar-se como defensor nesta Assembléia dos interesses dos grandes proprietários de terras (Annais da Assemblea ..., 1919, p. 146-147).

Nota-se, mais uma vez, ainda antes de 1930, que já aparece nos pronunciamentos de Vargas uma argumentação até então só defendida pelo grupo papelista: deveria o Estado intervir na economia para ampliar a produção. Observase mais claramente nessas ideias a defesa da intervenção estatal para garantir crescimento como o objetivo prioritário, e menos a defesa de políticas monetárias propriamente ditas.

Mas o papel do crédito e da política monetária para estimular a produção aparece quando Vargas afirma, em 1927 - aí já com o emprego do termo desenvolvimento, embora ainda em coexistência com o progresso de inspiração comtiana:

É um conceito vulgar que se impóe como um aforismo. Todo o desenvolvimento econômico deve ter por objetivo tornar a riqueza abundante pelo trabalho e ensinar o homem a usar essa riqueza pela cultura. Mas, se o dinheiro metálico é a medida dos valores, ele, no conceito corrente dos economistas, pela escassez de seu volume e pelas dificuldades de sua condição física, já não satisfaz à exigência do progresso econômico.
[...] Como imposição da própria necessidade, surgiu um elemento imaterial destinado a atingir os limites da flexibilidade, que é o crédito. Ele se expressa por um estado de confiança e segurança econômica. [...] A relação mercantil, diz um financista moderno, criou a operação sem dinheiro pela simples promessa de pagamento, que, por sua vez, se converte em riqueza, estimulando o trabalho e se transmutando em novos valores (Correio do Povo, 3/12/1927, p. 2).

Na década de 1950, Vargas, explicita isso ainda mais, recorrendo a argumento monetário típico do papelismo, dizendo:

Se estabelecermos um cotejo entre os vários aumentos da moeda em circulação e o custo de vida, veremos que não há proporção alguma. A relação entre os dois fenômenos não é básica [...]. Parece lógico que a solução para o problema não é restringir créditos e sim aumentar a nossa produção e riqueza (Vargas, 1950, p. 229).

A negação à Teoria Quantitativa da Moeda é aqui direta, o que justifica a menção crítica ao custo de vida, à inflação, como razão para controlar a quantidade de moeda ou disciplinar o governo restringindo seu poder monetário. Por outro lado, admite claramente o papel estimulador do crédito na economia, em vez de ver a moeda como neutra. 
O discurso não desprezava a estabilidade ou as regras de finanças sadias, porque, como a frase anterior explicita, a inflação não era vista como necessária consequência da quantidade de moeda. Mas o epicentro da ação estatal deveria ser incrementar as atividades produtivas. Afastava-se, assim, tanto dos princípios doutrinários do liberalismo como do positivismo, ou pelo menos, com relação a este último, relaxava enormemente o escopo das possibilidades de intervenção, ao afrouxar suas regras mais ortodoxas, como a crítica aos empréstimos e ao endividamento. Esse é outro exemplo de relação com os papelistas e com os antibulionistas e a Banking School, que, longe de ver o crédito como mera transferência de rendas de poupadores para investidores, como defendido pelos bulionistas, em particular por Ricardo, apreendem sua importância para impulsionar o ciclo de negócios.

No que se refere ao papel do mercado, aponta-se o laissez-faire como uma doutrina ultrapassada, incompatível com a realidade dos "países novos" (eufemismo para "menos desenvolvidos" ou, como se dirá mais tarde, "subdesenvolvidos"). Surpreende, por sua precocidade, a associação entre "grandes proprietários de terra" com liberalismo, a qual integrará mais tarde o imaginário desenvol- vimentista e reformista latino-americano, cuja ideologia responsabilizava o latifúndio e o imperialismo como as forças "retrógradas" contrárias ao "desenvolvimento nacional".

Pode-se interpretar nesse discurso: (a) uma crítica ao padrão-ouro, já que a "moeda metálica" já não é mais compatível com as exigências do crescimento econômico; (b) caberia ao governo estimular a produção, ou "tornar a riqueza abundante"; (c) o crédito para estimular a produção deveria ser incluído como um dos itens da agenda estatal, superando o dogma contrário ao endividamento para "dar exemplo" à sociedade.

Em certa interpretação, o crédito tal como aí aparece lembra a construção de Schumpeter: um instrumento para romper o fluxo circular simples e alavancar novas atividades produtivas, explicitando a não neutralidade da moeda: a "promessa de pagamento" no futuro rompia com as amarras do presente, limitantes do crescimento, uma vez que liberava a emissão de moeda do lastro ouro. Mais uma vez, cabe lembrar a semelhança dessas ideias com as do grupo papelista, único até então que as defendiam.

No ano seguinte, ao assumir a Presidência do Rio Grande do Sul, essas foram à prática com a criação, pelo Decreto $\mathrm{n}^{\mathrm{0}} 4.079$, de 22 de junho de 1928 , 
do Banco do Estado do Rio Grande do Sul. O banco estatal deveria diferenciarse, ter uma "organização mais ampla de um banco de Estado", já que sua finalidade seria "fazer a defesa de nossa produção, constituindo um propulsor da riqueza e do progresso" (Correio do Povo, 26/4/1928, p. 9). Pela proposta do governo, o banco deveria contar com uma carteira hipotecária e uma carteira econômica. À carteira hipotecária caberia, entre outras incumbências, conceder empréstimos aos produtores em prazo de até 30 anos, tendo como garantia suas propriedades, além de financiamentos de curto prazo de capital de giro, de armazenamento e venda da produção. Já à carteira econômica caberia realizar empréstimos sobre warrants e sobre notas promissórias para agricultores, pecuaristas e municípios, além do próprio Estado.

Mais incisiva, ainda, é a passagem seguinte em que o estímulo à produção industrial e agrícola por parte do Estado é, em uma metáfora, comparado a uma "marcha" (o que supóe disciplina, planejamento e, talvez, autoritarismo) rumo a uma "finalidade civilizadora", dando a entender que a História deveria seguir um rumo desejável, o qual não adviria espontaneamente, ou em decorrência das "forças de mercado", mas deveria ser construído pela ação concreta dos ho- mens - agentes não por iniciativa individual, mas por meio da instituiçẫo Estado.

É preciso amparar a produção, estimular a industria, desenvolver a circulaçâo de riqueza, disseminar a instrução, cuidar do saneamento público rural e urbano, facilitar a exploração de terras, desenvolver a agricultura, melhorar a pecuária, desbravar o caminho para a marcha do Rio Grande do Sul, no sentido de sua finalidade civilizadora (Rio Grande do Sul, 1928, p. 8).

Destarte, pode-se assinalar, finalmente, que a influência do papelismo nas origens do desenvolvimentismo, como aqui defendemos, assenta-se no fato de que os argumentos centrais de ambos apresentam semelhanças que dificilmente podem ser entendidas como fortuitas ou decorrência do acaso, hipótese que a pesquisa empírica em fontes nos sugere indubitavelmente respaldar. Todavia, deve-se também registrar que no papelismo a intervençáo da política econômica para o fomento das atividades produtivas vinculava-se principalmente aos ciclos ou às safras e entressafras de uma economia agrária. Essa concepção ajudou a abrir as portas para o desenvolvimentismo, mas esse o amplia e lhe dá nova dimensão. Neste último, a "finalidade civilizadora" aponta para um rumo, concebe a história como um fazer em caráter progressi- 
vo: o desenvolvimento, concebido como projeto a ser construído em longo prazo, e que gradualmente vai se associar a valores com forte apelo político, como "soberania nacional", "superação do atraso" e "igualdade social”, incorporados à ideologia desenvolvimentista.

Portanto essa posição, assim como a percepção dos impactos positivos que a moeda e o crédito poderiam ter para alcançar o desenvolvimento, teve no papelismo uma de suas fontes mais fecundas em seu nascedouro, mas foi ao amalgamar-se com a defesa de um projeto nacional de industrialização que tornou possível sua superação: o velho papelismo do final do século XIX gradualmente desapareceria a partir de 1930, cedendo espaço ao fenômeno histórico conhecido como "desenvolvimentismo" - marca da economia brasileira do século XX, que, embora com menor expressão em razão da hegemonia das teses liberais e neoliberais das últimas décadas, resiste e perdura até os dias atuais.

\section{Conclusão}

Descrevemos, neste artigo, as origens teóricas que o desenvolvimentismo teve no papelismo. Tal como neste último, o desenvolvimentismo, como o nome indica, prioriza o crescimento econô- mico ou o desenvolvimento. Para isso, percebe que a economia não pode ficar à mercê de automatismos de uma regra monetária, como o padrão-ouro, nem do funcionamento livre do mercado, que poderiam frear o ritmo de negócios, requerendo papel ativo do Estado por meio de políticas específicas.

Além disso, a ligação dos desenvolvimentistas com o papelismo se mostra particularmente importante quanto à percepção da influência da moeda sobre a economia real, negando a neutralidade da moeda, cara aos ortodoxos partidários da Teoria Quantitativa da Moeda. No caso do papelismo, isso se explicita na recusa em manter o padrão-ouro e na importância atribuída à política monetária interna, enquanto no desenvolvimentismo isso aparece na percepção de que o crédito pode e deve ser usado como ferramenta de estímulo ao crescimento da produção.

Tanto num caso quanto no outro, as duas vertentes de pensamento brasileiro têm origem no lado heterodoxo das controvérsias monetárias do século XIX, em particular nos antibulionistas, mas também na Banking School e na Birmingham School. Todavia, o debate brasileiro tomou conotaçóes próprias, ao adaptar-se a uma economia ainda predominantemente agroexportadora. E, 
no caso do papelismo, contribuiu para a formação, em suas origens, da corrente que representou a expressão da heterodoxia latino-americana ao trazer para objeto de estudo a historicidade do subdesenvolvimento e propor um conjunto de transformaçóes para superá-lo: o desenvolvimentismo. 


\section{Referências bibliográficas}

\section{Fontes primárias}

ANNAIS da Assemblea dos Representantes do Estado do Rio Grande do Sul. Porto Alegre: A Federaçáo, 1906-1930.

\section{ANNAIS da Câmara dos} Deputados do Congresso Nacional. Rio de Janeiro: Imprensa Oficial, 1891-1900.

ANNAIS do Senado. Rio de Janeiro: Imprensa Oficial, 1881-1888.

ANNAIS do Senado Federal. Rio de Janeiro: Imprensa Oficial, 1891-1900

CORREIO DO POVO. Porto Alegre: Brasil, 1895-1928.

RIO GRANDE DO SUL.

Mensagem enviada à Assembleia dos Representantes do Estado pelo

Exmo Sr. Dr. Antonio Augusto

Borges de Medeiros. Porto Alegre: A Federação, 1919.

RIO GRANDE DO SUL.

Mensagem à Assembleia de

Representantes do Estado do Rio

Grande do Sul enviada pelo Exmo.

Sr. Dr. Getúlio Vargas. Porto

Alegre: A Federação, 1928-30.

VARGAS. G. A politica

trabalhista no Brasil. Rio de

Janeiro: José Olympio, 1950.

\section{Outras referências}

AFTALION, F. \& PONCET, P.

Le monétarisme. Paris: PUF, 1984

ATTWOOD, T. Prosperity restored or reflections on the cause of the public distresses, and on the only means of relieving them. London: Baldwin, Cradock and Joy, and Logman Hurst and Co. 1817.

BARBOSA, R. O papel e a baixa do câmbio; um discurso histórico: 1891. Rio de Janeiro: Reler, 2005.

\section{BIELSCHOWSKY, R.}

Pensamento econômico brasileiro: $\mathrm{O}$ ciclo ideológico do desenvolvimentismo. Rio de Janeiro: IPA/INPES, 1988.

DEAN, P. A evolução O Capital (Crítica da Economia Política) das ideias econômicas. Rio de Janeiro: Zahar, 1980

FONSECA, P. C. D.

Gênese e precursores do desenvolvimentismo no Brasil.

Pesquisa \& Debate 15, v. 2, n. 26, p. 225-56, 2004
FONSECA, P. C. D. A controvérsia entre metalismo e papelismo e a gênese do desenvolvimentismo no Brasil. In: CONGRESSO NACIONAL DA ANPEC, 36., 2008, Salvador. Anais... Salvador, 2008.

FRANCO, G. H. B. Reforma monetária e instabilidade durante a transiçẫo republicana. Rio de Janeiro: BNDES, 1983.

FRANCO, G. H. B. Prefácio. In: BARBOSA, Rui. O papel e a baixa do câmbio; um discurso histórico: 1891. Rio de Janeiro: Reler, 2005.

FURTADO, C. Formação econômica do Brasil. 15. ed. São Paulo: Nacional, 1977.

GREMAUD, A. P. Das controvérsias teóricas à politica econômica: Pensamento econômico e economia brasileira no Segundo Império e na Primeira República. Tese (Doutorado em Economia). São Paulo: FEA/USP, 1997.

KEYNES, M (Org.). Ensaios sobre John Maynard Keynes. Rio de Janeiro: Paz e Terra, 1977.

MARX, K. O Capital, Livro 1. Rio de Janeiro: Civilizaçấo Brasileira, 1971.
MARX, K. O Capital, Livro 3. Rio de Janeiro: Civilização Brasileira, 1974

MAUÁ, Visconde de. Autobiografia. 3. ed. Rio de Janeiro: Topbooks, 1998.

MOLLO, M. L. As controvérsias monetárias do século XIX. Ensaios FEE, ano 15, n. 1, p. 8097, 1994.

MOLLO, M. L. Ortodoxia e heterodoxia monetárias: A questão da neutralidade da moeda. Revista de Economia Politica, v. 24, n. 3, p. 95, jul./ set. 2004 .

MÜLLER, E. Moedas e bancos no Rio de Janeiro no século XIX. 2004. Disponível em: <http:// www.ie.ufrj.br>.

\section{NEUHAUS, P. História} monetária do Brasil. Rio de Janeiro: IBMEC, 1975.

O'BRIEN, D. P. The classical economists revisited. Princeton: Princeton University Press, 2004

PRADO, L. C. D. A economia política das reformas econômicas da primeira década da república. Análise Econômica, n. 39, p. 93113, 2003 
RICARDO, D. Reply to Mr. Bosanquet's observations. The works of David Ricardo, J. R.

McCulloch (Ed.). London: John Murray, 1888.

RICARDO, D. The high price of bullion. Sraffa, P. (Ed.). The works and correspondence of David Ricardo. Cambridge: Cambridge University, 1951.

SAYERS, R. S. Monetary

thought and monetary policy in England. The Economic Journal, Dec. 1960.

SCHUMPETER, J. A. History of economic analysis, New York: Oxford University Press, 1954

SCHWARTZ, A. Banking School, Currency School, Free Banking School. The new palgrave: Money. London and Basingstoke: The Macmillan Press, 1989.

TOOKE, T. Tooke's evidence. Report from select committee on banks of issue, 1840.

VINER, J. Studies in the theory of international trade. New York: Harper and Brothers Publishers, 1937. Disponível em: <http:// www.econlib.org/library/ NPDBooks/Viner/vnSTT.html>

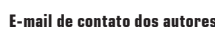

